\title{
Video Article \\ Neo-Islet Formation in Liver of Diabetic Mice by Helper-dependent Adenoviral Vector-Mediated Gene Transfer
}

\author{
Rongying $\mathrm{Li}^{1,2}$, Kazuhiro Oka ${ }^{1,2,3}$, Vijay Yechoor ${ }^{1,2,3}$ \\ ${ }^{1}$ Department of Medicine, Baylor College of Medicine \\ 2 Division of Diabetes, Endocrinology \& Metabolism, Diabetes \& Endocrinology Research Center, Baylor College of Medicine \\ ${ }^{3}$ Department of Molecular \& Cellular Biology, Baylor College of Medicine
}

Correspondence to: Vijay Yechoor at vyechoor@bcm.edu

URL: https://www.jove.com/video/4321

DOI: doi:10.3791/4321

Keywords: Medicine, Issue 68, Genetics, Physiology, Gene therapy, Neurogenin3, Betacellulin, helper-dependent adenoviral vectors, Type 1 diabetes, islet neogenesis

Date Published: 10/10/2012

Citation: Li, R., Oka, K., Yechoor, V. Neo-Islet Formation in Liver of Diabetic Mice by Helper-dependent Adenoviral Vector-Mediated Gene Transfer. J. Vis. Exp. (68), e4321, doi:10.3791/4321 (2012).

\section{Abstract}

Type 1 diabetes is caused by T cell-mediated autoimmune destruction of insulin-producing cells in the pancreas. Until now insulin replacement is still the major therapy, because islet transplantation has been limited by donor availability and by the need for long-term immunosuppression. Induced islet neogenesis by gene transfer of Neuogenin3 ( $\mathrm{Ngn} 3$ ), the islet lineage-defining specific transcription factor and Betacellulin (Btc), an islet growth factor has the potential to cure type 1 diabetes.

Adenoviral vectors (Ads) are highly efficient gene transfer vector; however, early generation Ads have several disadvantages for in vivo use. Helper-dependent Ads (HDAds) are the most advanced Ads that were developed to improve the safety profile of early generation of Ads and to prolong transgene expression ${ }^{1}$. They lack chronic toxicity because they lack viral coding sequences ${ }^{2-5}$ and retain only Ad cis elements necessary for vector replication and packaging. This allows cloning of up to $36 \mathrm{~kb}$ genes.

In this protocol, we describe the method to generate HDAd-Ngn3 and HDAd-Btc and to deliver these vectors into STZ-induced diabetic mice. Our results show that co-injection of HDAd-Ngn3 and HDAd-Btc induces 'neo islets' in the liver and reverses hyperglycemia in diabetic mice.

\section{Video Link}

The video component of this article can be found at https://www.jove.com/video/4321/

\section{Protocol}

\section{Clone the Therapeutic Genes into HDAd Shuttle Vector}

1. Clone mouse Ngn3 and Btc cDNAs into the pLPBL1 plasmid vector that contains a ubiquitous elongation factor-1 promoter (BOS) and a poly A signal. Upon completion, verify vectors by sequence analysis and then subclone these expression cassettes into $\mathrm{p} \triangle 28 \mathrm{HDAd}$ shuttle plasmid $^{6}$.

2. Digest HDAd shuttle vectors by Pmel to release the plasmid backbone, purify DNAs by phenol/chloroform/isoamyl alcohol extraction followed by ethanol precipitation and reconstitute with transfection-grade water.

\section{Helper-dependent Adenoviral Vector Production}

HDAd vector production involves multiple steps that need to be carefully followed for optimal results.

\subsection{Transfection}

1. Two days before transfection, seed $116 \mathrm{cells}^{7}$ into $6-\mathrm{cm}$ dish to reach $70-80 \%$ confluent on the day of transfection.

2. Three hours before transfection, remove medium and add $5 \mathrm{ml}$ of fresh growth medium [MEM supplemented with $10 \%$ FBS and $1 \%$ PSG (Penicillin, Streptomycin and Glutamine), Invitrogen].

3. Transfect 116 cells with $10 \mu \mathrm{g}$ DNA from Step 1.2), using the ProFectionR Mammalian Transfection kit from Promega according to manufacturer's instructions.

4. The next day, wash the cells with $1 \mathrm{ml}$ of growth medium 2 times. Add helper virus (HV) at 500 vector particles (vp) /cell to $0.1 \mathrm{ml}$ of PBS containing calcium and magnesium (PBS++) and overlay to the cells. Gently rock the dishes to evenly distribute the HV every 10 min.

5. After $60 \mathrm{~min}$, add $1.5 \mathrm{ml}$ of maintenance medium (MEM, 5\% FBS, $1 \% \mathrm{PSG}$ ).

6. Add another $1 \mathrm{ml}$ of maintenance medium the next day. 
7. Observe cells for CPE (Cytopathic Effect - cells become rounded and detached). Greater than $80 \%$ of cells should show CPE 2 days after infection.

8. Collect crude cell lysate (CVL, cells and medium), add $10 \%$ volume of $40 \%$ sucrose and store at $-80{ }^{\circ} \mathrm{C}$. The $\mathrm{CVL}$ is labeled as passage 0 (CVL-PO)

\subsection{Vector amplification}

1. Freeze $\left(-80^{\circ} \mathrm{C}, 3-5 \mathrm{~min}\right) /$ thaw $\left(37^{\circ} \mathrm{C}, 1-2 \mathrm{~min}\right) 3$ times.

2. Overlay $0.5 \mathrm{ml} \mathrm{CVL}$ supplemented with $\mathrm{HV}$ at $200 \mathrm{vp} / \mathrm{cell}$ to confluent 116 cells in $6-\mathrm{cm}$ dish, and rock the dish gently every 5 min. After 30 min, add $1 \mathrm{ml}$ maintenance medium.

3. Add $1 \mathrm{ml}$ of maintenance medium next day. 2 days later, most of the cells should show $\mathrm{CPE}$.

4. Collect the $\mathrm{CVL}$ and store at $-80^{\circ} \mathrm{C}$ (CVL-P1) as described for step 2.1.8).

5. Repeat the procedure for 3 times to get the CVL P2-P4.

6. Extract DNA (DNeasy Blood \& Tissue Kit, Qiagen) from $0.2 \mathrm{ml}$ of CVL collected at P1-P4, and analyze the vector amplification by qPCR using HV- and HDAd-specific primers (Table 1). Use the passage in which HDAd exponentially amplified relative to HV (P3 in Figure 2) for the subsequent procedure.

7. Co-infect $90 \%$ confluent 116 cells in $15 \mathrm{~cm}$ dish with $0.5 \mathrm{ml} \mathrm{CVL}$ and $\mathrm{HV}$ at $200 \mathrm{vp} / \mathrm{cell}$. Rock the dish gently every $5 \mathrm{~min}$. After $30 \mathrm{~min}$, add 10 $\mathrm{ml}$ of maintenance medium.

8. Add $5 \mathrm{ml}$ of maintenance medium after $24 \mathrm{hr}$

9. Collect cells by centrifugation at $1,500 \times \mathrm{g}$ for $5 \mathrm{~min}$ exactly $48 \mathrm{hr}$ after infection.

10. Re-suspend cells in $1 \mathrm{ml}$ of PBS++ containing $4 \%$ sucrose (P5) and freeze at $-80^{\circ} \mathrm{C}$.

\subsection{Large scale HDAd production}

1. To prepare 116 cells for infection in suspension cell culture, transfer confluent 116 cells in $8 \times 15$-cm dish into $3 \mathrm{~L}$ spinner flask and add suspension growth medium (Joklik modified MEM supplemented with $5 \% \mathrm{FBS}, 0.1 \mathrm{mg} / \mathrm{ml}$ hygromycin and $1 \% \mathrm{PSG}$ ) to final $1 \mathrm{~L}$, and incubate in a $\mathrm{CO}_{2}$ incubator with spinning at $60 \mathrm{rpm}^{8}$.

2. Add $0.5 \mathrm{~L}$ of fresh medium every day for 2 days (total $2 \mathrm{~L}$ ).

3. Count cells on the third day. Cells are ready to use if reaching to total cell number of $1 \times 10^{9}$.

4. Freeze/thaw P5 3 times.

5. Collect cells from $3 \mathrm{~L}$ spinner flask by centrifugation at $1,000 \mathrm{xg}$ for $5 \mathrm{~min}$. Save $100 \mathrm{ml}$ of supernatant to re-suspend the cells.

6. Transfer cells to a $250-\mathrm{ml}$ spinner flask. Add P5 and HV at $200 \mathrm{vp} /$ cell to cells and incubate for $1 \mathrm{hr}$ at $37^{\circ} \mathrm{C}$ at $60 \mathrm{rpm}$.

7. Transfer cells and medium to $3 \mathrm{~L}$ spinner flask, add $2 \mathrm{~L}$ suspension growth medium. Transfer $1 \mathrm{ml}$ cell suspension to a well in a 12 -well plate to observe the cells for CPE.

8. Incubate cells in spinner flask for 2 days in a $\mathrm{CO}_{2}$ incubator at $60 \mathrm{rpm}$.

9. Collect cells by centrifugation and re-suspend with $15 \mathrm{ml} 100 \mathrm{mM}$ Tris- $\mathrm{HCl}(\mathrm{pH} 8.0)$ and store at $-80^{\circ} \mathrm{C}(\mathrm{P} 6)$ until purification.

\subsection{Vector purification}

1. Add $1.0 \mathrm{ml}$ of $5 \%$ sodium deoxycholate to the $\mathrm{P} 6$. Mix gently and incubate for $30 \mathrm{~min}$ at room temperature.

2. Add $400 \mu \mathrm{l}$ of $2 \mathrm{M} \mathrm{MgCl}_{2}, 300 \mu \mathrm{l}$ of RNase $\mathrm{A}(10 \mathrm{mg} / \mathrm{ml})$, and $300 \mu \mathrm{l}$ of DNase I $(10 \mathrm{mg} / \mathrm{ml})$ and incubate at $37^{\circ} \mathrm{C}$ for $1 \mathrm{hr}$.

3. Centrifuge at $6,000 \times \mathrm{g}$ for $10 \mathrm{~min}$ at room temperature to collect supernatant.

4. Sterilize NVT 65 ultracentrifuge tubes (Beckman) under UV light for $1 \mathrm{hr}$ in tissue culture hood.

5. Add $2.8 \mathrm{ml}$ of low-density $\mathrm{CsCl}$ solution $(1.25 \mathrm{~g} / \mathrm{ml})$, underlay $2.8 \mathrm{ml}$ of high-density $\mathrm{CsCl}$ density solution $(1.41 \mathrm{~g} / \mathrm{ml})$ and then overlay $5-6 \mathrm{ml}$ of supernatant to fill the tube to the neck. Use $100 \mathrm{mM} \mathrm{Tris-HCl}(\mathrm{pH} 8.0)$ to fill the tube if necessary.

6. Centrifuge at $10^{\circ} \mathrm{C}$ for $30 \mathrm{~min}$ at $50,000 \mathrm{rpm}$ at $10^{\circ} \mathrm{C}$ with Beckman LE-80K using NVT-65 rotor.

7. Wipe the area with $70 \%$ ethanol for needle puncture, and collect the lower opalescent band with a 3-ml syringe equipped with $22-\mathrm{G}$ needle by side puncture (Figure 3a). Sometimes a very faint helper band can be seen below the more prominent vector band. Try to obtain as much of the vector band as possible, without the helper band. It is acceptable at this step even if some of the helper band is aspirated, as it will be separated at the subsequent overnight centrifugation that follows.

8. Place the collected bands into a new sterilized ultracentrifuge tubes. Fill the tubes to the neck by overlaying $1.35 \mathrm{~g} / \mathrm{ml} \mathrm{CsCl}$ density solution.

9. Centrifuge at $10^{\circ} \mathrm{C}$ at $50,000 \mathrm{rpm}$ overnight. Collect the opalescent band (Figure $3 \mathbf{b}$ ).

10. Transfer the band into a dialysis cassette (Slide-a-Lyzer, 10,000 MWCO, Thermo-scientific).

11. Dialyze against $3 \mathrm{~L}$ of autoclaved $10 \mathrm{mM}$ Tis- $\mathrm{HCl}, \mathrm{pH} 7.2$ containing $2 \mathrm{mM} \mathrm{MgCl}_{2}$ and $4 \%$ sucrose at $4{ }^{\circ} \mathrm{C}$ overnight.

12. Remove the HDAd vector from dialysis cassette. Aliquot $20 \mu \mathrm{l}$ for physical titer and $50 \mu \mathrm{l}$ for DNA characterization. (Note: For Ngn3 vector, repeat "P6" three times to obtain sufficient vector since the yield of HDAd-Ngn3 is poor compared to HDAd-Btc or HDAd-empty.)

\subsection{Characterization of HDAd vectors}

1. Determine the physical titer (vp/ml) using optical density (OD). Add $20 \mu \mathrm{l}$ vector or $20 \mu$ dialysis buffer to $380 \mu \mathrm{l}$ TE buffer containing $0.1 \%$ SDS and incubate at $56^{\circ} \mathrm{C}$ for $20 \mathrm{~min}$. Measure $\mathrm{OD}$ at $260 \mathrm{~nm}$. The physical titer $=$ OD260 $\times 1.1 \times 10^{12} \times 20(\mathrm{vp} / \mathrm{ml})$.

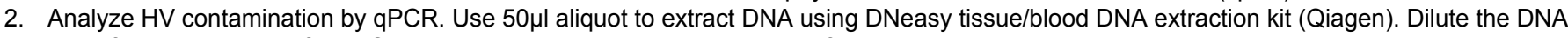
1000 -fold and take $5 \mu \mathrm{l}$ for qPCR analysis using helper and vector-specific primers (Table 1). The helper contamination should be less than $1 \%$, as shown in Figure $\mathbf{4 A}$.

3. Use Southern blot to analyze vector structure. Perform Southern blot analysis ${ }^{10}$ using a probe for the inverted terminal repeat (ITR). The representative result is shown in Figure 4B.

4. Determine in vitro efficacy. Infect known number of 116 cells in a 12 well plate with HDAd vector at 1000 vp/cell in quadruplicate. Harvest the cells after $48 \mathrm{hr}$ and extract RNA to determine expression of Ngn3 and Btc mRNAs by qRT-PCR (Table 1). Representative results are shown in Figure 5. 


\section{Treatment of Diabetic Mice by HDAd-Ngn3 and -Btc}

\subsection{Induction of diabetes in mice and injection of HDAd vectors}

1. Preparation of STZ: Prepare $0.1 \mathrm{M}$ citrate buffer, and adjust $\mathrm{PH}$ to $4.3-4.5$. Filter this through a $0.22 \mathrm{~mm}$ syringe filter. Using sterile water dilute this to $0.01 \mathrm{M} \mathrm{Na}$ Citrate $\mathrm{pH}$ 4.2-4.5. Dissolve appropriate amount of STZ (Sigma) in this solution to achieve a final concentration of $12.5 \mathrm{mg} / \mathrm{ml}$. At this concentration there is no precipitation. Keep this STZ solution at $4{ }^{\circ} \mathrm{C}$ till used. Bring the temperature of the injecting solution to room temperature immediately prior to injection. The STZ solution should be prepared fresh each day and injected within 5-10 min of being dissolved.

2. Inject this STZ solution intraperitoneally ( $10 \mu \mathrm{l} / \mathrm{gm}$ to achieve a dose of $125 \mu \mathrm{g} / \mathrm{g}$ body weight), in the evening between $5-7 \mathrm{pm}$ (before the lights are turned off in the mouse facility and the mice start feeding actively), on two consecutive days ${ }^{9}$.

\subsection{Monitoring mice glucose and injection of HDAd vectors.}

1. Fast mice for $6 \mathrm{hr}$ and measure body weight and blood glucose weekly until mice have hyperglycemia ( $\geq 250 \mathrm{mg} / \mathrm{dl})$. Use a One Touch glucometer for blood collected by tail snip. Once blood glucose is $\geq 250 \mathrm{mg} / \mathrm{dl}$, recheck the blood glucose again in $48 \mathrm{hr}$ after a $6 \mathrm{hr}$ fast to ensure persistent hyperglycemia and blood glucose is within the target range for treatment: $250-500 \mathrm{mg} / \mathrm{dl}$.

2. Treat mice with persistent hyperglycemia by a single intravenous injection of HDAd vectors via tail vein. The total vector dose is $6 \times 10^{11} \mathrm{vp}$ for all treatment groups (in $0.25 \mathrm{ml}$ ): $5 \times 10^{11} \mathrm{vp} \mathrm{Ngn3}+1 \times 10^{11} \mathrm{vp} \mathrm{Btc}$ for combination group; $5 \times 10^{11} \mathrm{vp} \mathrm{Ngn3}+1 \times 10^{11} \mathrm{vp}$ for Ngn3 group; and $1 \times 10^{11} \mathrm{vp} \mathrm{Btc}+5 \times 10^{11} \mathrm{vp}$ empty vector for Btc group and $6 \times 10^{11} \mathrm{vp}$ empty vector for control group.

3. Tail vein injection. Put mice into Tailveiner restrainer (TV-150, Braintree Scientific Inc.), and use warm water to dilate the tail veins, clean the tail with $70 \%$ alcohol. Hold tail below the injection site between thumb and forefinger of the hand, use another hand for injection. Before injection make sure there are no bubbles in the syringe (using $30^{1 / 2} \mathrm{G}$ needle and $1 \mathrm{ml}$ syringe). Insert needle and inject the vector slowly. If the needle is in the vein, a flash of blood may be seen in the hub of the needle and also there is no resistance during injection. After removing the needle, hold the injection site with gauze to stop bleeding before returning mice to cage.

If the needle is not in the vein there is significant resistance to injection and a little subcutaneous wheal arises. At this time remove the needle and try again at a different site.

\subsection{Analysis of effects of HDAd-Ngn3+HDAd-Btc treatment.}

1. Monitor $6 \mathrm{hr}$ fasting glucose and body weight weekly after vector treatment.

2. Collect blood from the saphenous vein or tail vein in the leg every 2 weeks to assay insulin (Mouse Insulin ELISA kit, Mercodia) and liver enzymes (AST and ALT Infinity Reagents, Thermo Scientific) using commercial kits.

1. Place the mouse in an uncapped $50 \mathrm{ml}$ Falcon tube with holes made in the closed end.

2. The mouse's head is at the closed end of the tube and legs and tail at the open side of the tube. To collect blood from the left leg, extend the left leg outside of the tube and gently pinch the skin of the thigh between the thumb and forefinger to immobilize the leg.

3. Use a shaver to remove the hair from the shin/lower leg area, to expose the saphenous vein, which is present on the lateral side of the lower leg. Clean the shaved skin with $70 \%$ alcohol and let it dry.

4. Puncture the saphenous vein with a 25 gauge needle, Collect the blood with Microvette CB300 tube (Sarstedt) and put the tubes on the ice.

5. Press the puncture site with gauze to stop bleeding before returning the mice to the cages.

6. Centrifuge the tubes at $3,000 \times \mathrm{g}$ for $5 \mathrm{~min}$, take the supernatant and store at $-20{ }^{\circ} \mathrm{C}$ for further analysis.

\subsection{Perform glucose tolerance test (GTT) at 6 weeks after treatment.}

1. Dissolved D-glucose (Sigma) in distilled water to make $15 \%$ glucose $(15 \mathrm{~g} / 100 \mathrm{ml})$ and sterile filter the glucose.

2. Fast mice for $6 \mathrm{hr}$. Use warm pad to warm the mice and collect the blood ( $0 \mathrm{~min}$ time point). Then inject $1.5 \mathrm{~g} / \mathrm{kg}$ of D-Glucose i.p ( $10 \mu \mathrm{l} / \mathrm{g}$ of $15 \%$ glucose).

3. Collect blood at $15,30,60,120 \mathrm{~min}$

4. Measure the glucose and insulin in all these samples.

\subsection{Tissue analysis to assess the expression of the vectors and assess the induction of islet neogenesis.}

In all these steps the controls that are required to reliably interpret the results include: (1) Empty vector treated diabetic mice (2) non-diabetic mice and (3) non-diabetic pancreas serving as a positive control for the expression of the islet specific hormones and transcription factors.

1. Harvest liver and pancreas at 3 and 6 weeks after treatment. Divide into 2 pieces, the first for snap freezing in liquid nitrogen and storage at $-80{ }^{\circ} \mathrm{C}$ for RNA and protein extraction, and the second to fix with $10 \%$ formalin overnight for immunohistochemistry analysis.

2. Extract RNA by a standard protocol and analyze expression of islet specific hormones and transcriptional factors, along with Ngn3 and Btc to confirm vector expression, in the liver by qRT-PCR using specific primers ${ }^{9,10}$.

3. Extract insulin and c-peptide from the liver by acid-ethanol extraction method and quantify by a commercial ELISA kit (ultra sensitive Insulin assay, Mercodia, C-peptide ELISA kit, Wako).

4. Perform immunostaining for islet specific hormones (Insulin, Glucagon, PP, SST) along with islet specific transcription factors in paraffin embedded sections ${ }^{9,10}$. The expression of $\mathrm{Ngn} 3$ and Btc can also be confirmed by immunostaining.

\section{Representative Results}

We cloned Ngn3 and Btc cDNA into $\mathrm{p} \Delta 28$ vectors driven by ubiquitous promoter elF2a (BOS) and generated HDAd-Ngn3 and HDAd-Btc. As shown in Figure 2, relative HV contamination decreased significantly (implying more vector amplification and less helper amplification) at 
passage 3. Therefore, we used $\mathrm{P} 3$ for subsequent vector production. After the first $\mathrm{CsCl}$ discontinuous gradient and ultracentrifugation, we collected the lowest vector band and then collected the opalescent band corresponding to HDAd vector in the second ultracentrifugation (Figure 3). The purified HDAd vector had less than $1 \%$ of HV contamination (Figure 4A) by qPCR and had no helper contamination visible on southern blotting (Figure 4B), indicating sufficient quality for vector infusion into mice. Further analysis included transgene expression by infection of 116 cells. The mRNA expression levels of $\mathrm{Ngn} 3$ and Btc were higher in vector infected cells by over 10,000-fold compared with those in non infected cells (Figure 5).

HDAd-Ngn3 and -Btc were then administered to STZ-induced diabetic mice via tail vein injection with empty vector injected and HDAd-Btc injected diabetic mice serving as negative control. Hyperglycemia was reversed and glucose-stimulated insulin secretion was restored in mice treated with both HDAd-Ngn3 and HDAd-Btc but not in mice treated with single gene vector or control empty vector (Figure 6). The HDAd-Ngn3Btc treatment induced islet neogenesis and this was quantitated by assaying total insulin and c-peptide content (Figure 6E) with non-diabetic, diabetic empty vector treated mice serving as controls. The presence of c-peptide and insulin in equimolar ratios confirms that the insulin being detected in the liver is indeed being synthesized in the liver. RT-qPCR confirmed that the liver of HDAd-Ngn3-Btc treated mice expressed all the islet-specific hormones and transcription factors ${ }^{9}$. Immunohistochemistry showed insulin positive cells in the liver of mice treated with HDAd$\mathrm{Ngn} 3$ and HDAd-Btc, but no insulin positive cells were observed in mice treated with control vector (Figure 7). We also confirmed that there were no residual islets in the pancreas of the Ngn3-Btc treated mice as compared to the numerous islets in non-diabetic pancreas. Vector (Ngn3 and $\mathrm{Btc}$ ) along with islet specific lineage transcription factor ( $\mathrm{Pdx}-1$ and Nkx6.1) expression was also assessed by immunostaining of the liver (Figure 7).

\section{Day 1 - Cyto-Pathic Effect (CPE)}

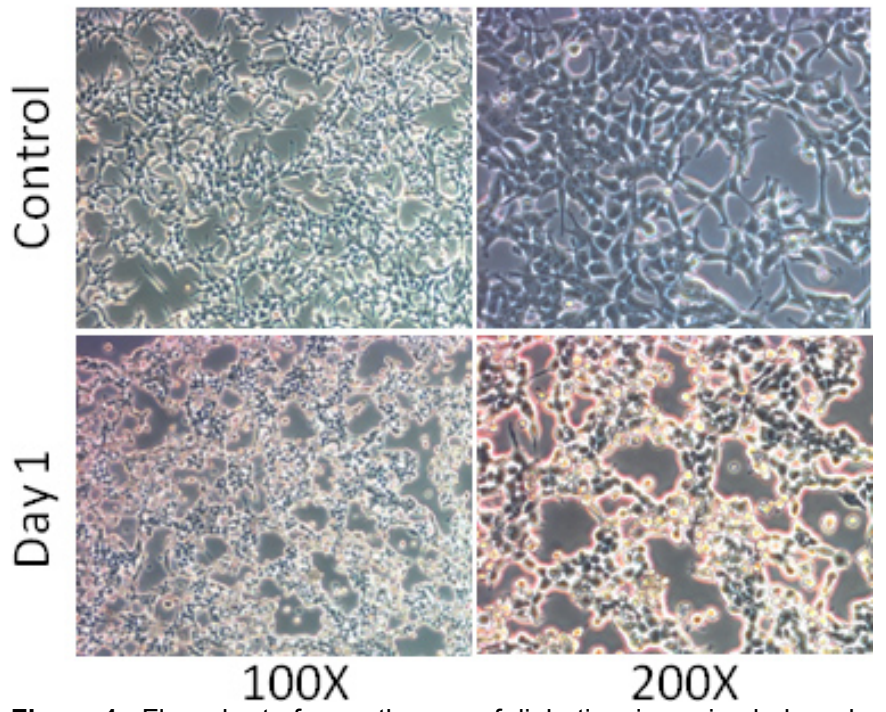

Figure 1. Flow chart of gene therapy of diabetic mice using helper-dependent virus system. First, Ngn3 and Btc, in a cassette driven by a ubiquitous BOS promoter, are cloned into HDAd shuttle $(\mathrm{p} \Delta 28)$ vectors. HDAd is produced by several steps including transfection, serial passages of amplification, and a large scale infection followed by vector purification. After characterizing the quality, HDAds are injected intravenously into STZ-induced diabetic mice via tail vein. The effects of treatment are assessed by measuring glucose, body weight, GTT and by analyses of gene expression in the liver.

\section{Day 2 - Cyto-Pathic Effect (CPE)}

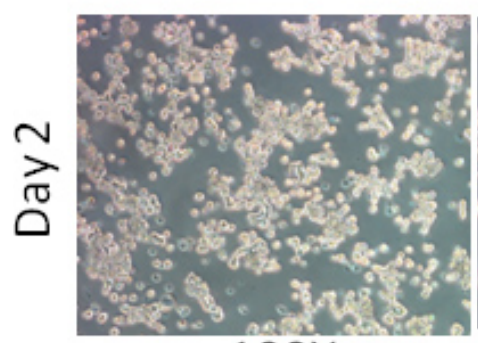

$100 X$

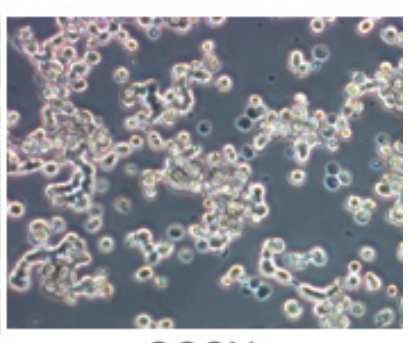

$200 X$

Figure 2. Determination HDAd vector amplification. DNA is extracted from passage P0 to P4 using DNA extraction kits (Qiagen). DNA is diluted 1,000 -fold and $5 \mu$ I DNA is used for real time PCR (qPCR). Helper and vector-specific primers are used. Standard curves are generated by serial dilutions $\left(10^{-5}\right.$ to $\left.1 \mathrm{ng} / \mathrm{ml}\right)$ of HDAd shuttle vector plasmid and HV plasmid (top panels). Using the standard curves and the Ct values for the vector and helper virus copy number is calculated and the ratio of HDAd/HV is plotted as a percentage of the total virus (helper + HDAd). Hence, relative vector amplification is calculated as: [vector copy number / (vector + helper virus copy number)]. In the example shown (bottom panel) HDAd vector amplification plateaued at P4, while the relative HDAd/HV is increasing at P3. Therefore, P3 is selected for the subsequent step. 

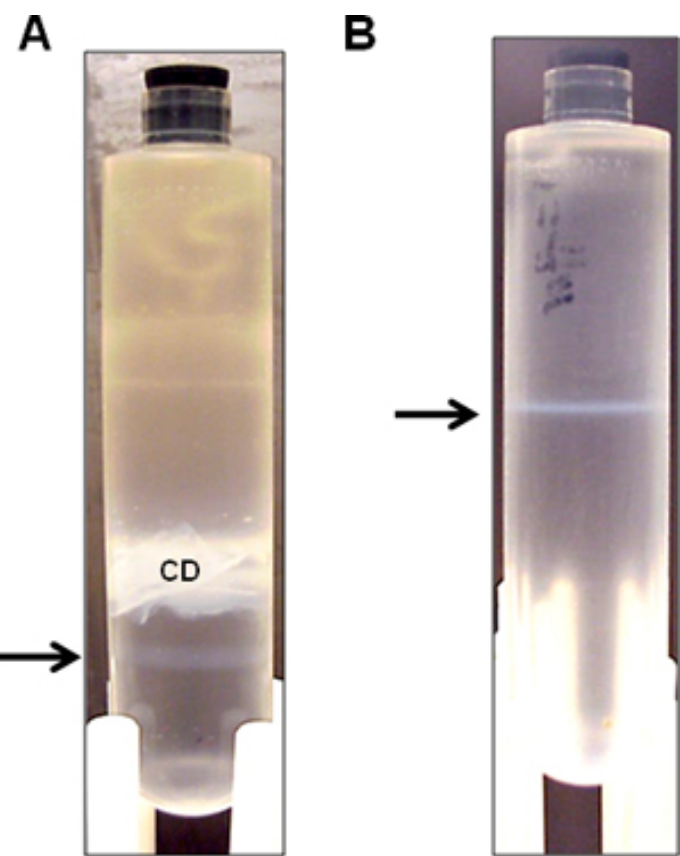

Figure 3. Representative HDAd vector bands after discontinuous $\mathrm{CsCl}$ density ultracentrifugation. HDAd vector is purified from a $3 \mathrm{~L}$ spinner culture over sequential $\mathrm{CsCl}$ density gradient. (A) After first density gradient ultracentrifugation, a single opalescent vector band is visible (arrow) below opaque cell debris (CD). The opalescent band (arrow) is collected for the second density gradient centrifugation. (B) After the second density gradient ultracentrifugation, the opalescent band (arrow) is collected for dialysis.
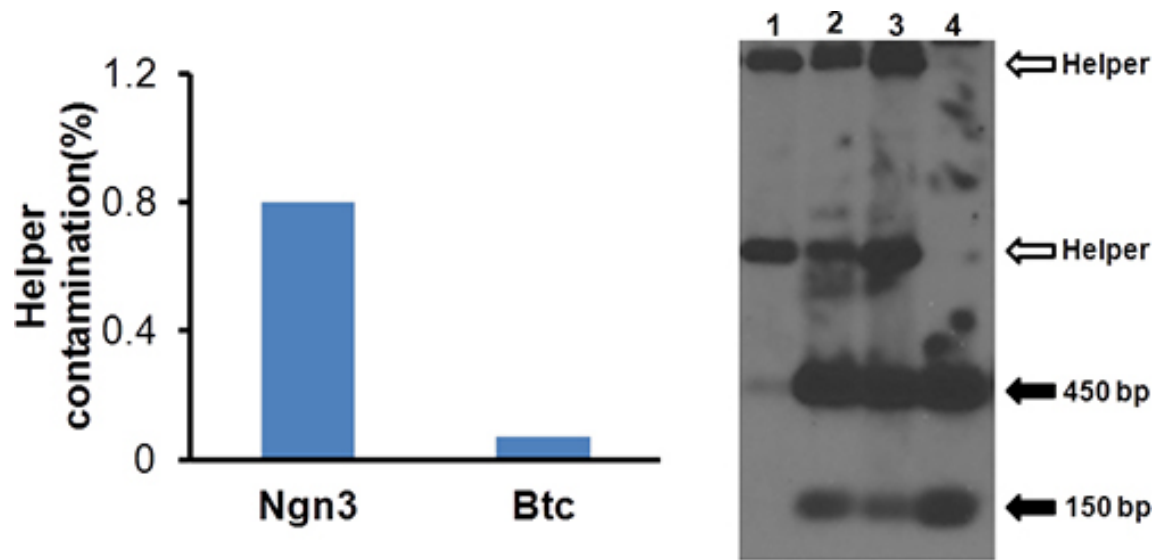

Figure 4. Analysis of helper virus contamination. DNA is extracted from $50 \mu$ l purified virus and helper contamination is assessed as in Figure 2. The figure shows helper contamination of HDAd-Ngn3 and HDAd-Btc is less than $1 \%$.

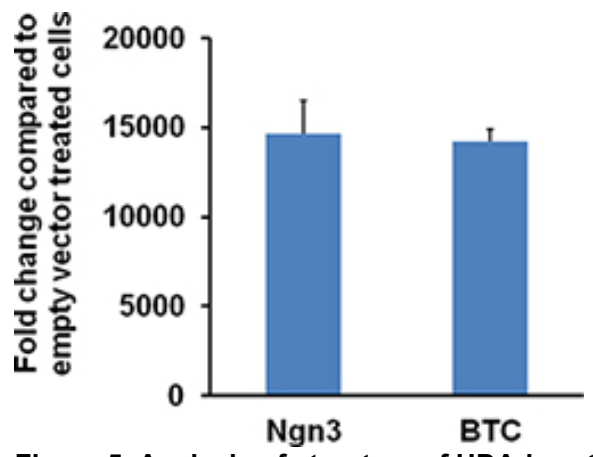

Figure 5. Analysis of structure of HDAd vector. Southern blot is performed as described previously (Oka K, et al.). Lane 1: DNA from helper virus; Lane 2: DNA from P3; Lane 3: DNA from P4; Lane 4: purified vectopr. Open arrows indicate the helper virus derived bands and the filled arrows indicate the ITR bands derived from the HDAd vector. 
A

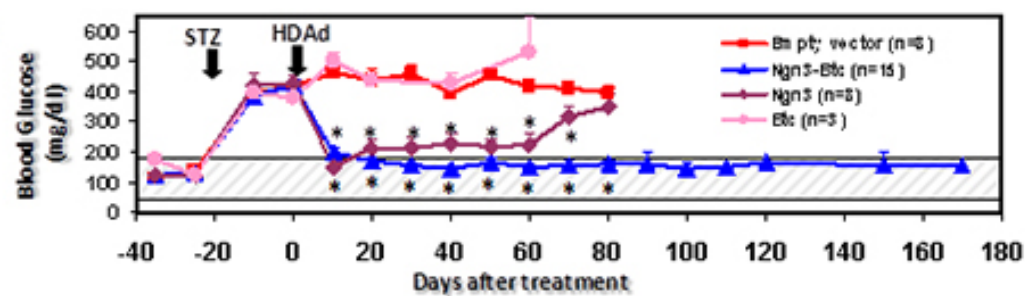

B

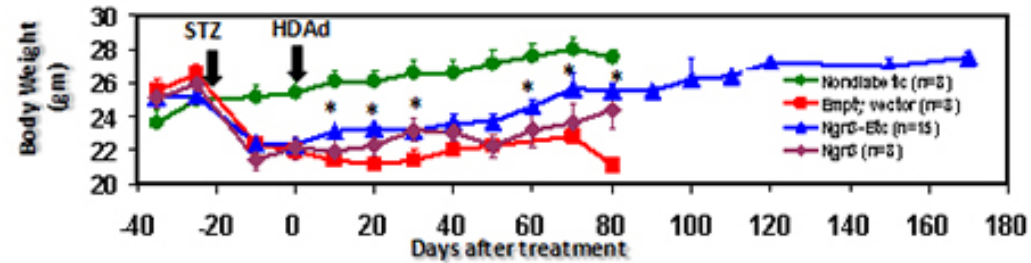

C

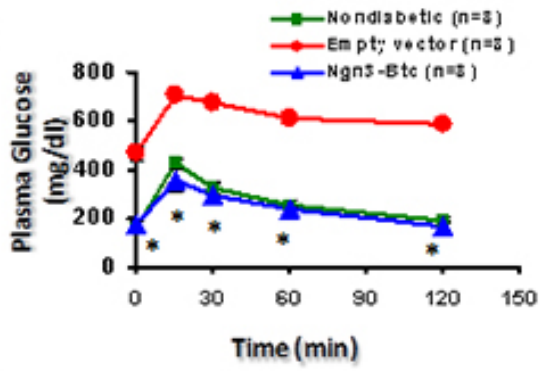

D

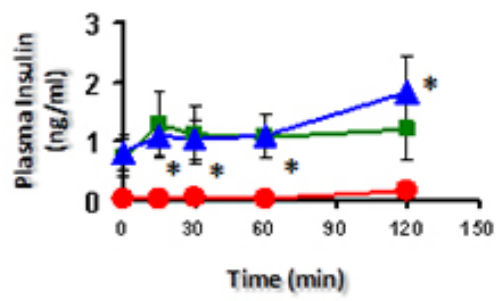

E
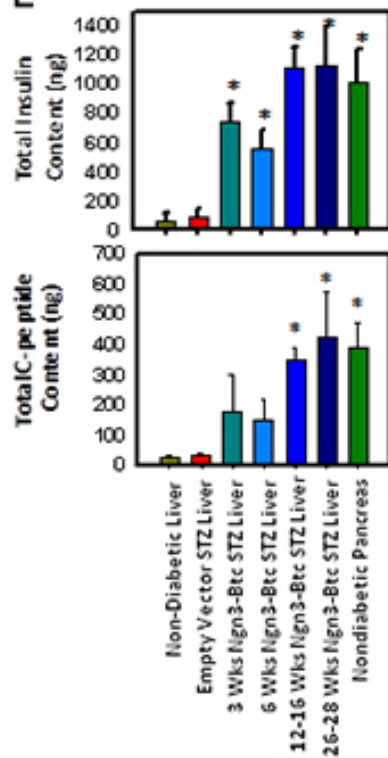

Figure 6. Expression level of Ngn3 or Btc in 116 cells infected with HDAd-Ngn3 or HDAd-Btc vector. 116 Cells in a 12 well plates are infected with HDAd-Ngn3 or HDAd-Btc or empty vector at 1000 vp/cell for 2 days. Cells are harvested and total RNA is extracted using Trizol reagent. qRT-PCR is performed using Ngn3- or Btc-specific primers. The relative Ngn3 or Btc mRNA expression increased by over 10,000-fold in cells infected with HDAd-Ngn3 or HDAd-Btc. The figure is reprinted from Dev.Cell 2009 Mar; 16 (3) : 358-73; Yechoor et. al., with permission from Elsevier. 
A Insulin in Liver

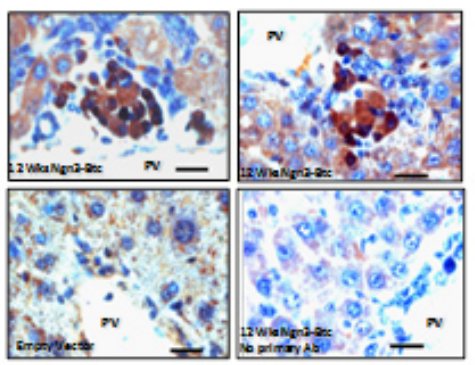

C $\quad \mathrm{Ngn} 3$ in Liver
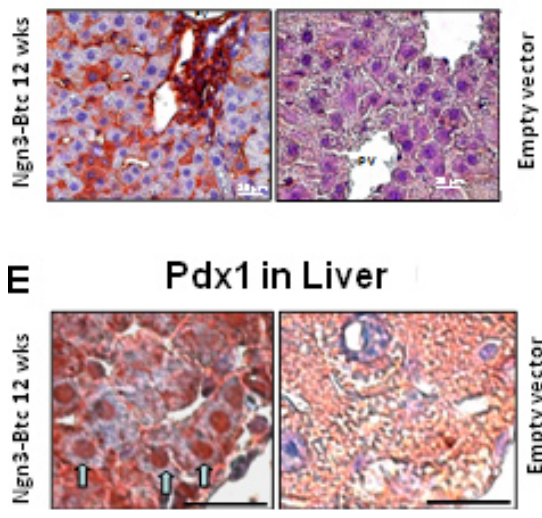

B Insulin in Pancreas
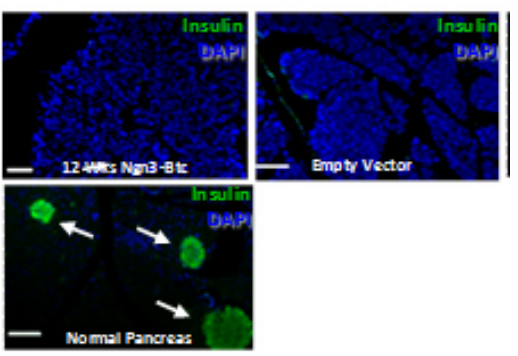

D

Btc in Liver

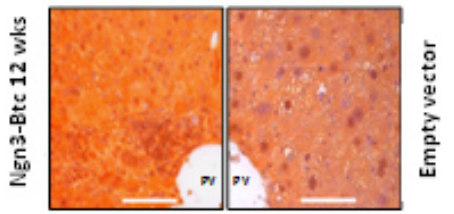

F $\quad$ Nkx6.1 in Liver

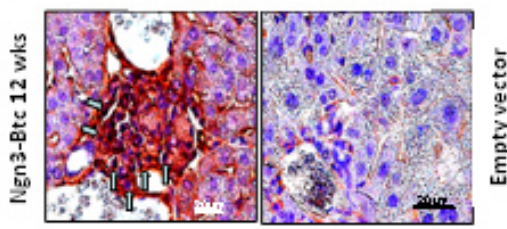

Nuclear localization of immunoreactive Pdx-1 in the Predominantly nuclesr locslization of immunoresctive Nikr 6.1 periportal cells in the Ngn3-Btctreated mice (arrows) in the periportal cells in the Ngn3-Btc trested mice (arrows)

Figure 7. Gene transfer of HDAd-Ngn3 and HDAd-Btc into STZ-induced diabetic mice leads to reversal of diabetes and induction of islet neogenesis in the liver. (A) Plasma glucose and (B) body weight of STZ-induced diabetic mice treated with HDAd-Ngn3 and HDAd-Btc. (C) Plasma glucose and insulin during an IP-GTT at 6 weeks after treatment. (D) Representative insulin staining in the liver 12 weeks after treatment. " $p<0.05$ (vs. empty vector group). The figure is reprinted from Dev. Cell 2009 Mar; 16 (3) : 358-73; Yechoor et al., with permission from Elsevier.

\begin{tabular}{|l|l|l|l|}
\hline name & forward primer & \multicolumn{1}{l|}{ reverse primer } \\
\hline helper & GACCATCAATCTTGACGACC & ATGTCGCTTTCCAGAACCC \\
\hline vector & TTGGGCGTAACCGAGTAAG & ACTTCCTACCCATAAGCTCC \\
\hline Ngn3 & AAGAGCGAGTTGGCACTCAG & TCTGAGTCAGTGCCCAGATG & \\
\hline Btc & GCACAGGTACCACCCCTAGA & TGAACACCACCATGACCACT \\
\hline
\end{tabular}

Table 1. Primer sequences.

\section{Discussion}

HDAds have been developed to overcome the weakness of early generation Ads and to harness for gene therapy application. However, technical challenges remain. For example, HDAd requires HV for HDAd's packaging and vector amplification is not as efficient as early generation Ads. HV is a first generation Ad and any contamination of HV compromise the effectiveness of HDAd. Therefore, highly efficient transfection and optimal conditions for each serial passage are critical. Another critical parameter for vector production is which passage (P1-P4) should be used for subsequent passage 5 that is directly used as inoculum for suspension cells. To our experience, the best results are obtained by using the passage by which HDAd vector proportion is dramatically increased in the following passage (P3 in Figure 2). The yield of HDAd vectors depends on transgene cassettes. During vector production, both transgenes are expressed because both genes are under ubiquitous promoter. Ngn3 is a transcription factor and Btc is a growth factor, which suggests that HDAd vector expressing transcription factor which may influence cell lineage inhibits vector amplification while that expressing growth hormone helps in vector replication and packaging.

With diabetes assuming epidemic proportions, new approaches to restore b-cell mass are needed. In this report, we describe methods to harness the advantages of HDAd vectors to effect gene transfer of islet lineage-defining transcription factor, Ngn3 along with the islet growth factor, betacellulin to induce islet neogenesis in periportal regions of the liver. To assess the efficacy of this, it is important to choose mice with stable hyperglycemia and ensure that appropriate controls are always included. For this gene transfer experiments, the empty vector treated diabetic mice should always be utilized. In addition, using HDAd-Ngn3 and HDAd-Btc individually treated diabetic mice serves to test the individual contribution of these two genes in islet neogenesis. As our data demonstrates that $\mathrm{Ngn} 3$ alone is sufficient to induce islet neogenesis, but the addition of the growth factor, Btc, serves to augment the response leading to robust induction of islet neogenesis. It is also important to 
test that the vector expression is indeed achieved in the target tissue, the liver and also to demonstrate that the insulin assayed in the plasma of treated mice is not coming from residual islets in the pancreas, by demonstrating the absence of pancreatic islets in the diabetic mice.

In summary, the advantage of the HDAd-vector system for gene transfer lies in its high cloning capacity, efficient transduction and long lasting gene expression in the liver with minimum chronic toxicity as well as its nature of non-integration of vector genome into the host chromosome. The primary limitations are the complex steps involved in its generation and its in vivo application is primarily limited to the liver with the most popular Ad serotype 5. Islet neogenesis can be induced to fully restore plasma insulin and glucose tolerance in diabetic mice by inducing islet neogenesis in the liver by gene transfer of islet lineage-defining transcription factor, Ngn3 along with the islet growth factor, betacellulin. In this report, we show the optimal protocol to generate high quality HDAd-Ngn3 and HDAd-Btc, and demonstrate techniques to induce and assess islet neogenesis in the livers of diabetic mice to reverse hyperglycemia.

Footnote: The viral vectors and the cell lines described here are available from the Vector Production Core Laboratory, Diabetes Research Center, Baylor College of Medicine (http://www.bcm.edu/mcb/index.cfm?pmid=7731). Some commercial kits are also available for generating HDAd viruses (e.g. Microbix biosystems Inc.).

\section{Disclosures}

No conflicts of interest declared.

\section{Acknowledgements}

This work was supported by grants from the NIH: R03 DK089061-01 (VKY); NIH: K08 DK068391 (VKY); the Diabetes and Endocrinology Research Center-(DERC - P30DK079638) at Baylor College of Medicine, a Pilot \& Feasibility grant from the DERC (VKY); Juvenile Diabetes Research Foundation: JDRF Award \# 5-2006-134 (VKY).

\section{References}

1. Parks, R.J., et al. A helper-dependent adenovirus vector system: removal of helper virus by Cre-mediated excision of the viral packaging signal. Proc. Natl. Acad. Sci. U. S. A. 93, 13565-13570 (1996).

2. Kim, I.H., Jozkowicz, A., Piedra, P.A., Oka, K., \& Chan, L. Lifetime correction of genetic deficiency in mice with a single injection of helperdependent adenoviral vector. Proc. Natl. Acad. Sci. U.S.A. 98, 13282-13287 (2001).

3. Belalcazar, L.M., et al. Long-term stable expression of human apolipoprotein A-I mediated by helper-dependent adenovirus gene transfer inhibits atherosclerosis progression and remodels atherosclerotic plaques in a mouse model of familial hypercholesterolemia. Circulation. 107, 2726-2732 (2003).

4. Oka, K., et al. Long-term stable correction of low-density lipoprotein receptor-deficient mice with a helper-dependent adenoviral vector expressing the very low-density lipoprotein receptor. Circulation. 103, 1274-1281 (2001).

5. Nomura, S., et al. Low-density lipoprotein receptor gene therapy using helper-dependent adenovirus produces long-term protection against atherosclerosis in a mouse model of familial hypercholesterolemia. Gene Ther. 11, 1540-1548 (2004).

6. Ng, P., et al. A high-efficiency Cre/loxP-based system for construction of adenoviral vectors. Hum. Gene Ther. 10, 2667-2672 (1999).

7. Palmer, D. \& Ng, P. Improved system for helper-dependent adenoviral vector production. Mol. Ther. 8, 846-852 (2003).

8. Oka, K. \& Chan, L. Helper-Dependent Adenoviral Vectors In: Current Protocols in Molecular Biology. 16.24.1-16.24.23 (2005).

9. Yechoor, V., et al. Neurogenin3 is sufficient for transdetermination of hepatic progenitor cells into neo-islets in vivo but not transdifferentiation of hepatocytes. Dev. Cell. 16, 358-373 (2009).

10. Yechoor, V., et al. Gene Therapy with Neurogenin 3 and Betacellulin Reverses Major Metabolic Problems in Insulin-Deficient Diabetic Mice. Endocrinology., (2009). 